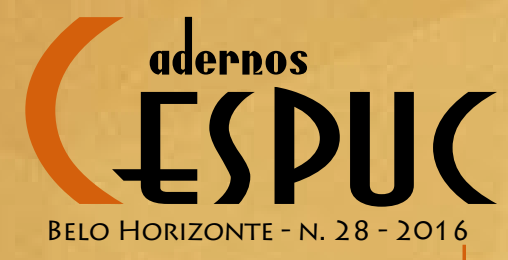

\title{
NIETZSCHE E CLASTRES: UM PARALELO
}

João Gabriel Cunha

Amanda Marques

Universidade Federal Fluminense UFF. Graduandos em Antropologia. Orientação: Professor Antonio Carlos Raphael Barbosa.

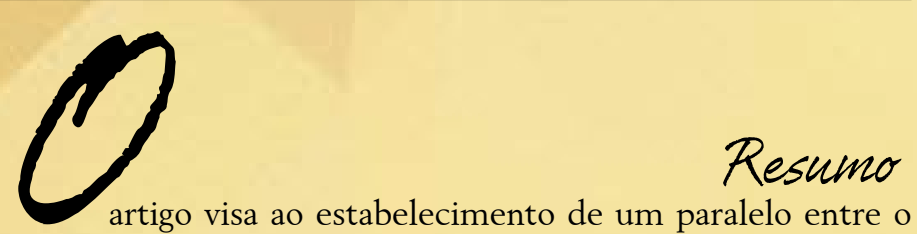
filósofo Friedrich Nietzsche e o etnólogo Pierre Clastres, em especial a partir da atividade que atribuem à cultura e dos sentidos subversivos de suas propostas com relação aos valores político-culturais ocidentais. Assim, em um primeiro momento, nosso objetivo é abordar algumas questões postas pela obra de Nietzsche, sobretudo a partir de seu conceito de cultura, que acreditamos estar a serviço da compreensão dos fenômenos do ressentimento e da má consciência. Valemo-nos do eixo interpretativo apontado por Gilles Deleuze em Nietzsche e a filosofia e da obra Genealogia da moral, de Nietzsche. Além disso, abordaremos a noção de "sociedade contra o Estado", elaborada por Clastres para dar conta da ontologia política dos Guayaki. Nossa intenção é perceber seu potencial de transformar os significados políticos ocidentais, e também em que medida a filosofia nietzscheana se elabora em um sentido "contra o Estado".

Palavras-chave: Nietzsche. Deleuze. Clastres. Filosofia. Antropologia.

Acreditamos existirem pontos de ressonância entre Nietzsche e Clastres. Faremos aqui uma aproximação experimental que pretende realizar três movimentos de convergência: 1) ver o sentido pré-histórico da cultura em Nietzsche como formador da memória, na tortura entre os Guayaki como inscrição da lei que esconjura o Estado; 2) trazer à tona o potencial subversivo da noção de sociedade contra o Estado de Pierre Clastres, que transvalora a ideia dominante de Estado na história da cultura ocidental, abrindo a possibilidade de um sentido político afirmativo à existência; e 3) a percepção da filosofia política contra o Estado de Nietzsche. Propomos o primeiro 
ponto através do eixo interpretativo apresentado por Deleuze em Nietzsche e a filosofia (1962). Além disso, apoiamo-nos na entrevista concedida por Clastres em 1974, em que ele afirma: "Posso reconhecer e afirmar claramente a influência de Nietzsche, sobretudo da Genealogia da Moral" (CLASTRES, 2012, p. 266).

Vamos inicialmente a alguns aspectos fundamentais de Nietzsche e a filosofia. Comecemos pela ideia de força, já que ela é primordial: tudo o que existe é uma composição de forças em relação. Isso, de imediato, implica outra compreensão do corpo. Sendo ele biológico, social, político, é composto por forças que se relacionam dominando ou obedecendo umas às outras; as que subjugam são chamadas de forças ativas e as que se submetem, de forças reativas. As forças em relação têm tanto uma quantidade, como uma qualidade correspondente à diferença de quantidade. Então não há em si forças ativas ou reativas, tais qualidades aparecem como resultado de uma relação em que há o predomínio de uma delas. As forças ativas são as forças criativas, isto é, são forças superiores que vão até o limite do que podem, afirmadoras de sua diferença. Já as forças reativas são forças utilitárias, de conservação e limitação, que negam as forças ativas. $\mathrm{O}$ que determina a relação das forças, o que está no seu princípio, é a vontade de potência. A vontade de potência é o componente interno das forças e se manifesta tanto nas que são ativas quanto nas reativas, e assim é qualificada respectivamente como afirmativa ou negativa. Conforme nos apresenta Deleuze, o problema crítico de Nietzsche é "o valor dos valores, a avaliação donde procede o seu valor" (DELEUZE, 2001, p. 6), daí o conceito de vontade de potência como origem da qualidade das forças ser de onde provêm o sentido e o valor dos valores. Dessa forma, a interpretação de um fenômeno diria respeito à determinação da qualidade da força responsável por seu sentido - se é ativa ou reativa; e a avaliação do valor dos valores, à determinação da vontade de potência que se exprime - afirmativa ou negativa. Ou seja, os valores são inseparáveis da vontade de potência de onde retiram seu valor: "o que Nietzsche chama nobre, elevado, senhor, é o que quer a força ativa, quer a vontade afirmativa. O que ele chama mesquinho, vil, escravo é o que quer a força reativa, quer a vontade negativa" (DELEUZE, 2001, p. 84).

Nietzsche constata que a história ocidental - história da decadência -, é marcada por uma disposição negativa diante da vida, o que atesta a vitória das forças reativas sobre as forças ativas. A questão que ele se põe, e que é retomada por Deleuze, 
é: "como é que as forças reativas triunfam?" (DELEUZE, 2001, p 87). A resposta dada por Nietzsche é que elas não se impõem porque compõem uma força superior, mas através de uma operação de subtração ou divisão, que é sempre pautada em uma ficção, mistificação ou falsificação. As forças reativas separam as forças ativas do que podem, retiram a atividade das forças ativas, sua vontade de potência afirmativa e criadora, através da construção da ficção de uma força separada do que pode. Ou seja, o triunfo das forças reativas acontece porque elas criam uma ficção que diz respeito à natureza das forças, a ideia de que se poderia escolher não ser força ativa. Mas há ainda outros elementos que se relacionam à disposição negativa que marca a história do ocidente. Nesse sentido, são descritas, na Genealogia da moral (1888), as realizações do sacerdote judeu e do sacerdote cristão como criadores de sentido para a existência humana.

O sacerdote judeu é apontado como o criador do ressentimento. Ele é o personagem conceitual que procede invertendo os valores aristocráticos, transformando "bom e ruim" em "bom e mau". Para os nobres, "bom" correspondia a poderoso, belo, feliz, caro aos deuses; e "ruim" era apenas uma criação secundária diante da imagem plebeia. Esse é o esforço de demonstração da primeira dissertação da Genealogia da moral: a transvaloração judaica, que, como denominada por Nietzsche, consistiu na inversão desses valores, passando a corresponder "bom" a miserável, impotente, baixo, sofredor, etc., e "nobres" a maus, cruéis, lascivos. O sacerdote judeu, tendo como fonte de valoração o espírito de vingança, empreendeu a moralização das forças, "a revolta dos escravos na moral: aquela rebelião que tem atrás de si dois mil anos de história, e que hoje perdemos de vista, porque foi vitoriosa" (NIETZSCHE, 1998, p. 26). A rebelião escrava na moral não é um acontecimento da história, mas seu princípio, marcado pela expulsão da vontade de potência afirmativa - do que decorre um mundo com um sentido proveniente da negação.

O sacerdote judeu age movido por uma vontade de potência negativa. É ele o responsável pela elaboração do ressentimento, que atribui um sentido de caráter acusador à existência. A acusação é a responsabilização do outro pelo mal-estar da existência. Primeiramente, nega-se o outro, e a afirmação de si é o fruto posterior dessa negação. O sacerdote judeu configura o ressentimento como perspectiva de avaliação da vida, e o tipo que se constitui a partir dessa interpretação é dono de uma memória prodigiosa, ao mesmo tempo em que 
vingativo e promotor de uma acusação perpétua. $\mathrm{O}$ homem do ressentimento é incapaz de admirar, amar e respeitar. É passivo, e por viver imerso em si e no passado, só é capaz de "re-sentir", marcado que é pela incapacidade de reação.

Além disso, o ressentimento, como máquina de produção de sentido, organização dos corpos, das relações dos homens entre si, é o primeiro momento de manifestação do niilismo. O segundo momento da manifestação do niilismo é marcado pelo surgimento da má consciência, que apresenta dois aspectos. $\mathrm{O}$ primeiro diz respeito à origem da má consciência, quando o homem passou a viver sob prescrições sociais, logo sob a pressão de assumir condutas dóceis. Os instintos do homem, mesmo aí, não deixaram de fazer exigências, mas, pelo fato de não mais ser possível descarregarem-se para fora, interiorizaram-se. Em certa medida, aí se encontra o momento do surgimento da alma, do alargamento do mundo interior. Podemos concluir, então, que apenas posteriormente a má consciência foi entrelaçada à religião, como realização do sacerdote cristão.

O sacerdote cristão cria a má consciência como maneira de sentir e viver através da culpa, em que o sentido da dor é atribuído a si mesmo. Vê-se como o sacerdote judeu e o cristão estão em íntima relação: o sacerdote cristão, ao elaborar a má consciência, a interiorização da dor, está desdobrando a inversão de valores judaicos, cujo aspecto é a culpabilização da existência. Para o sacerdote judeu a culpa é do outro, para o sacerdote cristão a culpa é minha. É ele que promove a mudança da direção do ressentimento contra si próprio. Aqui a dor se interioriza. Ela se torna pecado e constitui o sentido da culpa. Para Nietzsche, do ódio judeu brotou um novo amor como sua coroa, e esse amor buscava as mesmas metas daquele ódio: a figura do animal sacrificial, Cristo morto na cruz pelos nossos pecados. Através da figura de um salvador, os judeus puderam alcançar a meta final de seus anseios de vingança, alguém a nos pôr em uma eterna dívida impagável, o redentor de nossas vidas em pecado diário.

Nossa hipótese é que o conceito de cultura foi elaborado por Nietzsche a serviço da compreensão dos fenômenos do ressentimento e da má consciência. Cultura, para ele, não é um conceito antropológico, a fim de compreender a diversidade do fenômeno humano, mas é filosófico, e dotado de três sentidos que coexistem: pré-histórico, histórico e póshistórico. O homem não é capaz de viver fora da cultura. A atribuição de valores é uma dimensão constante e inseparável 
da existência humana. Para Nietzsche, atribuir valores envolveu o adestramento, e essa seria propriamente a tarefa da cultura. A atividade da cultura "propõe-se adestrar o homem, quer dizer, tornar as forças reativas aptas para servir, para ser agidas" (DELEUZE, 2001, p. 210).

O primeiro sentido destacado por Deleuze, na leitura que faz de Nietzsche, é o da cultura como constituinte, ou seja, a cultura pretendendo constituir o que não está na história. Aqui não há lugar para ressentimento, má consciência e culpa. A cultura, no sentido pré-histórico, consiste no adestramento e na seleção do homem, e o homem é adestrado a partir da tortura e da dor. O adestramento é violento. A atividade da cultura se exerce nas forças reativas, impondo sobre os sujeitos hábitos, leis e costumes, que devem ser reproduzidos. No sentido pré-histórico, tem-se o homem como animal essencialmente esquecido, e a cultura deve construir uma memória para esse animal esquecido, deve "criar um animal que pode fazer promessas” (NIETZSCHE, 1998, p. 47).

A criação dessa memória se dá pelo sistema de crueldade. $\mathrm{O}$ sistema de crueldade produz essa memória a partir da dor. A cultura constitui uma relação entre dano e dor. Como sistema de crueldade, ela inscreve signos no corpo através do castigo, e, devido à sua repetição, cria, assim, a potência de lembrar - lembrança da palavra empenhada, que é a possibilidade de prometer pelo futuro. O que se designa como castigo é a repetição de um mecanismo de constituição de memória; que, pela produção de dor para reparar a palavra não honrada, tem como objetivo reforçar a consciência. Aqui a cultura quer constituir no homem a potência de responder por si no tempo. Esse é seu caráter seletivo: formar um homem capaz de prometer, de criar um compromisso com o futuro. Temse aqui a formação de uma memória do futuro, da vontade, das palavras. O produto final dessa cultura é o homem ativo. A relação credor-devedor "exprime a atividade da cultura no seu processo de adestramento ou de formação" (DELEUZE, 2001, p. 202). E a dívida aparece como elemento essencial, constitutivo da experiência humana.

O segundo sentido da cultura é ser dominada pelo que a constitui, o sentido é dado pelo predomínio das forças reativas, há a caída da atividade na reatividade. A cultura no sentido histórico é o sentido combatido por Nietzsche, quando o homem, por intermédio de ficções, falseia a ação ativa. As forças reativas se enxertam nas atividades da cultura, relegando-se o 
adestramento e a seleção às forças reativas. Aqui o conteúdo da cultura produzida prevalece sobre a produção da lei, e a responsabilidade da dívida torna-se culpabilidade. Passa-se a viver do ponto de vista da assimetria, e a dívida torna-se um meio para o aprisionamento do homem, o meio de submissão ao pecado. Aqui seleciona-se a reatividade, o escravo e a submissão: "utilizam-se processos de seleção para destruir os fortes, para selecionar os fracos, os sofredores ou os escravos. (...) não é mais do que um meio de conservar, de organizar, de propagar a vida reativa" (DELEUZE, 2001, p. 208).

Por último, o terceiro sentido é constituir algo que ultrapassa a própria cultura. O sentido fundamental da cultura póshistórica é a produção do homem soberano, não mais subjugado a hábitos, leis ou costumes que deveriam ser reproduzidos, mas criador. Aqui, o último-homem, o europeu apegado aos seus caros valores cristãos apequenadores, dá lugar ao além-dohomem ou super-homem nietzscheano: o indivíduo soberano, que se liberta da própria cultura e cria seus próprios valores, não respondendo mais pelos valores estabelecidos. Ele é livre e capaz para a formulação de suas próprias leis, para a criação de sua própria existência e sentido.

Apresentados esses conceitos de cultura que Deleuze observa em Nietzsche, acreditamos que é possível uma aproximação do primeiro sentido de cultura como sistema de crueldade, com o contexto etnográfico dos rituais de iniciação descritos por Clastres no ensaio intitulado "Da tortura nas sociedades primitivas". Tanto em Nietzsche como em Clastres, a tortura age constituindo a faculdade da memória, através de uma relação entre lei, escrita e corpo. Em Nietzsche, além disso, os mecanismos de tortura responsáveis pela constituição do homem como animal capaz de prometer também se relacionam à dominação das paixões - que, nos Guayaki, agem inibindo a paixão do poder, o desejo de governar. Já Clastres nos faz ver que a tortura entre os índios Guayaki converte o próprio corpo dos iniciados em um obstáculo ao esquecimento da lei que esconjura o Estado: "A lei primitiva, cruelmente ensinada, é uma proibição à desigualdade de que todos se lembrarão. Substância inerente ao grupo, a lei primitiva faz-se substância do indivíduo, vontade pessoal de cumprir a lei" (CLASTRES, 2012, p. 199). 
Neste segundo momento, deslocaremos o nosso rumo para as filosofias políticas traçadas pelos dois autores, de modo que nosso paralelo passará a se situar em um registro argumentativo guiado, dentre outras, pela ideia de subversão. Assim, poderíamos encarar tanto Nietzsche como Clastres como pensadores intempestivos, provocadores de revoluções de significado, ou "inimigos da convenção", para dizer nas palavras do escritor inglês Lawrence (1998, p. 234). Eles "vislumbram o caos" no mundo das convenções necessárias que naturalizamos e às quais nos apegamos, e, entre outras coisas, isso é dar-se conta de que nossos caros significados, atribuídos aos seres e às coisas, não são fixos, mas, justamente, atribuíveis, e assim podem adquirir outros sentidos. Assim, observamos a intempestividade de Nietzsche na sua intenção de conferir outro sentido à vida, afirmá-la em sua imanência, e devir, descolada de quaisquer valores superiores; e a de Clastres observamos na possibilidade que abre de transformação dos significados políticos ocidentais.

Com referência à época de Nietzsche, seu pensamento, tido como extemporâneo, vem resgatar os valores trágicos abafados pelo pensamento socrático-platônico, que inaugura uma cultura decadente e com caráter racionalista. Um dos problemas no estabelecimento de tal dissociação diz respeito à pretensão da filosofia, em toda a sua vontade de verdade, em negar-se como criação, isto é, a crença de que a partir da contemplação é possível acessar a essência dos seres e das coisas, o que na verdade suprime a sua temporalidade.

Assim, o que Nietzsche chama de "platonismo" diz respeito, resguardando as devidas diferenças, à filosofia metafísica, de Sócrates a Kant, que se institui sobre dualismos que negam a vida em sua integralidade. A título de exemplo, podemos perceber que, na história da filosofia, o devir foi desvalorizado em detrimento do ser, assim como o corpo foi em relação à alma. Isto é, nosso ponto é que a imutabilidade, assumindo a roupagem de vários conceitos, é sempre posta em primeiro lugar que a multiplicidade e a variação. Nessa lógica de pensamento, a vida possui um estatuto de culpa, que é salvo pela contemplação de ideais transcendentes a ela. Esse movimento de valorização de algo superior à vida inaugura a história do niilismo concebido como pensamento, que, antes de tudo, nega a vida.

A proposta de Nietzsche é justamente superar essa negação da vida através da subversão dos dualismos, instaurando a filosofia trágica e, consequentemente, outra relação do homem com a existência. Podemos considerar Nietzsche subversivo, 
dentre outras coisas, porque, em vez de valorizar um polo desses dualismos, como, por exemplo, o devir ao invés do ser, ele propõe sua ultrapassagem através de sentidos radicalmente diferentes, descartando todos os ideais superiores à vida como através da proposição de que o ser é a afirmação do devir. Dessa forma, ele afirma a vida em sua multiplicidade. $\mathrm{O}$ caráter subversivo de Nietzsche se relaciona às concepções radicalmente diferentes de filosofia, história, cultura, política e, sobretudo, de vida que ele propõe.

No que diz respeito a Pierre Clastres, sua trajetória tem início no âmbito da filosofia, tendo se convertido posteriormente à etnologia, e, no fim de sua obra, realizou uma filosofia política indígena. Uma das hipóteses do pensamento de Clastres é que a civilização ocidental está fundada na oposição entre razão e desatino, o que estabelece uma linha de separação entre civilizados e primitivos. Clastres pretende realizar, então, uma nova etnologia, que não faz uma mera descrição dos Outros orientada pelas categorias ocidentais, mas cria um novo pensamento a partir do diálogo, fruto do encontro nós/outros, que justamente rompe com essa separação ontológica, e que “(...) permitisse forjar uma nova linguagem infinitamente mais rica; uma etnologia que, superando essa oposição tão central em torno da qual se edificou e se afirmou nossa civilização, se transformaria ela mesma num novo pensamento" (CLASTRES, 1968, p. 90).

Como etnólogo, realizou trabalho etnográfico na América do Sul e propôs, em plena Paris da década de 1960, pensarmos a organização política de alguns grupos indígenas a partir da noção de "sociedade contra o Estado". Usualmente na antropologia política de sua época, tomava-se o dualismo com Estado ou sem, para dar conta das cosmologias indígenas, que nos escritos antropológicos apareciam desprovidas de "fé, lei e rei". Isto é, o critério ocidental da organização estatal e do poder centralizado era o parâmetro para a compreensão dos sistemas políticos indígenas. Com possíveis traços evolucionistas, essa compreensão do outro resvala em um primitivismo, à medida que a concepção da organização social em termos de ausência indica um caminho progressivo ao surgimento do Estado.

Clastres subverte esse dualismo, ultrapassando-o ao propor o sentido de contra o Estado, já que na verdade não há uma ausência nessas sociedades, mas propriamente uma organização social que deseja a todo custo evitar a figura do Um. Podemos desdobrar o sentido desse Um, começando pela ideia de 
identidade, que marca a história da filosofia ocidental, e, sobretudo, está presente no modo de organização específico do ocidente, em que o Estado, sendo Um, se assume capaz de representar a todos, ou seja, a multiplicidade. Enfim, parece-nos que essa representação empreendida pelo $U m$, isto é, o Estado, suprime as singularidades. Tanto Nietzsche como Clastres criam estratégias de boicote à representação ao se aliarem às inúmeras linguagens outras que escapam a essa unificação que as desqualifica.

A sociedade contra o Estado empreende um impedimento ativo do Estado, que está diretamente ligado à relação de dominação do homem pelo homem: "o que os selvagens nos mostram é o esforço permanente para impedir os chefes de serem chefes, é a recusa da unificação, é o trabalho de conjuração do Um, do Estado" (CLASTRES, 2012, p. 231). Isso que se percebe em nível institucional localiza-se na esfera dos desejos, e assim as sociedades primitivas esconjuram o Estado, através do desejo de que o chefe não exerça jamais poder coercitivo. Nessas sociedades, os chefes são dotados não de poder mas de influência e prestígio, exercendo mediação e não comando. A guerra é um cenário etnográfico em que se pode, excepcionalmente, observar o exercício de poder como comando. Então, não é como se os chefes indígenas nunca experimentassem ou desejassem um poder transcendente ao da sociedade. Após os conflitos, imediatamente o chefe retorna à sua posição usual. No entanto, caso ele, a despeito dos desejos da sociedade, pretenda atender a seus desejos individuais, e guerrear unicamente a partir da motivação destes, será então abandonado pela sociedade.

Observamos o sentido subversivo de Clastres na noção "sociedade contra o Estado", à medida que, no encontro com o pensamento indígena, os valores ocidentais experimentam uma possível metamorfose de seus sentidos político-culturais. Assumindo essa noção como um conceito da filosofia indígena, ela se torna um vetor que indica a expressão de mundos possíveis (VIVEIROS DE CASTRO, 2002), através da qual podemos colocar em questão valores ocidentais profundamente arraigados, como a noção de Estado. Para, além disso, parecenos haver aqui uma consonância entre a filosofia política indígena e a filosofia antipolítica de Nietzsche.

Usualmente as críticas direcionadas às considerações de Nietzsche a respeito de sua posição política tratam-no como um grande conservador por não encontrarem em seus escritos nada 


\section{deter}

ESPUC

BELO HORIZONTE - N. 28 - 2016

mais que seu distanciamento da esfera política e dos valores de seu tempo. A autora Céline Denat (2013, p. 41) apresenta uma leitura antipolítica do afastamento de Nietzsche. De acordo com seu argumento, apenas pseudofilósofos participam de debates políticos, enquanto os filósofos de espírito livre, isto é, libertos dos valores históricos ocidentais, colocam em questão esses próprios valores, sobre os quais a política se apoia. Para Nietzsche, a política não é uma esfera autônoma da sociedade, não há política em si. Ele a concebe como um fenômeno de superfície, através do qual se pode observar um sintoma do que ele chama de cultura decadente: "Nietzsche nega a autonomia da esfera política para reconduzi-la à 'questão fundamental' da cultura e dos valores. (...) Nietzsche pretende radicalizar e estender sua significação, ao pensar numa 'grande política' que supere as noções de Estado (...)” (DENAT, 2013, p. 70). Podemos concluir, então, que ele deseja se afastar dos sentidos usuais que acompanham a esfera política, propondo uma antipolítica, um pensamento que é mesmo contra o Estado, ao radicalizar as noções de Estado, igualdade, democracia, nacionalismo.

\section{NIETZSCHE AND CLASTRES:}

A PARALLEL

\section{ABSTRACT}

This paper aims to establish a parallel between the philosopher Friedrich Nietzsche and the ethnologist Pierre Clastres, particularly from the activity they attribute to culture, and the subversive sense of their proposals with regard to Western political and cultural values. At first, we aim to deal with some questions posed by Nietzsche's work, especially his concept of culture, which we believe is in the service of understanding the phenomena of resentment and of bad conscience. We have used the interpretive axis pointed out by Gilles Deleuze in Nietzsche and Philosophy, and Nietzsche's On The Genealogy of Morals. In addition, we discuss the notion of "society against the state" elaborated by Clastres to account for Guayaki's political ontology. Our intention is to realize 
its potentiality to transform the Western political meanings, and also to what extent the Nietzschean philosophy is elaborated in an "against the state" sense.

Keywords: Nietzsche. Deleuze. Clastres. Philosophy. Anthropology.

\section{REFERÊNCIAS}

CLASTRES, Pierre. "Entre o silêncio e o diálogo". In. LéviSTRAUSS. L'arc. São Paulo: Documentos, 1968.

CLASTRES, Pierre. Sociedade contra o Estado. Tradução de Theo Santiago. São Paulo: Cosac Naify, 2012.

DELEUZE, Gilles. Nietzsche e a filosofia. Tradução de Antônio M. Magalhães. Porto: Rés-Editora, 2001.

DENAT, Céline. F. Nietzsche ou a "política" como "antipolítica". Tradução de Wilson Antonio Frezzatti Jr. Cadernos Nietzsche, São Paulo, n. 32, p. 41-71, 2013.

LAWRENCE, David. Selected critical writings. London: Oxford university press, 1998.

NIETZSCHE, Friedrich. Genealogia da Moral. Tradução, notas e posfácio de Paulo César de Souza. São Paulo: Companhia das Letras, 1998.

VIVEIROS DE CASTRO, Eduardo. O nativo relativo. MANA, Rio de Janeiro, v. 8, n.1, p. 113-148, fev. 2002.

Recebido em: 08/06/2015

Aceito em: 05/1 1/2015 